\title{
Expression of androgen receptor in non-muscle-invasive bladder cancer predicts the preventive effect of androgen deprivation therapy on tumor recurrence
}

\author{
Koji Izumi ${ }^{1,2, *}$, Yusuke Ito1,*, Hiroshi Miyamoto ${ }^{3}$, Yasuhide Miyoshi ${ }^{4}$, Junichi Ota², \\ Masatoshi Moriyama², Tetsuo Murai', Hiroyuki Hayashi', Yoshiaki Inayama7, \\ Kenichi Ohashi ${ }^{8}$, Masahiro Yao ${ }^{1}$ and Hiroji Uemura ${ }^{4}$ \\ ${ }^{1}$ Department of Urology, Yokohama City University Graduate School of Medicine, Yokohama, Japan \\ 2 Department of Urology, Yokohama Municipal Citizen's Hospital, Yokohama, Japan \\ ${ }^{3}$ Departments of Pathology and Urology, Johns Hopkins University School of Medicine, Baltimore, MD, USA \\ ${ }^{4}$ Department of Urology, Yokohama City University Medical Center, Yokohama, Japan \\ ${ }^{5}$ Department of Urology, International Goodwill Hospital, Yokohama, Japan \\ ${ }^{6}$ Department of Pathology, Yokohama Municipal Citizen's Hospital, Yokohama, Japan \\ 7 Department of Pathology, Yokohama City University Medical Center, Yokohama, Japan \\ ${ }^{8}$ Department of Pathology, Yokohama City University Graduate School of Medicine, Yokohama, Japan \\ * These authors have contributed equally to this work \\ Correspondence to: Koji Izumi, email: koji.izumi522@gmail.com \\ Keywords: bladder cancer, recurrence, androgen receptor, androgen deprivation therapy \\ Received: November 04, 2015 Accepted: January 29, $2016 \quad$ Published: February 12, 2016
}

\section{ABSTRACT}

Our recent retrospective study revealed a significantly reduced risk of bladder cancer $(B C)$ recurrence in men who received androgen deprivation therapy (ADT) for their prostate cancer. However, whether androgen receptor (AR) signals contributed to the preventive effect of ADT remained unclear because ADT could reduce serum estrogens as well. The purpose of this study is to investigate the associations between the expression of AR/estrogen receptors (ERs) and BC recurrence in patients treated with ADT. We immunohistochemically stained $72 \mathrm{BCs}$ and 42 corresponding normal urothelial tissues. AR/ERa/ERß were positive in $44(61 \%) / 22(31 \%) / 39(54 \%)$ tumors and $35(83 \%) / 24(57 \%) / 34(81 \%)$ corresponding normal urothelial tissues, respectively. There were no statistically significant correlations between AR/ERa/ ER $\beta$ expression and clinicopathological features of BC. With a median follow-up of 31.3 months, $12(43 \%)$ of 28 patients with AR-negative tumor versus $11(23 \%)$ of 44 patients with AR-positive tumor experienced BC recurrence. Thus, patients with ARpositive tumor had a significantly lower risk of $B C$ recurrence $(P=0.031)$, compared with those with AR-negative tumor. Meanwhile, the expression of ERa/ERß in tumors and that of $A R / E R a / E R \beta$ in normal urothelial tissues were not significantly correlated with BC recurrence. A multivariate analysis revealed AR positivity in tumors as an independent prognosticator (hazard ratio: 0.27; 95\% confidence interval: 0.11-0.67) for $B C$ recurrence. These results indicate that ADT prevents $B C$ recurrence via the AR pathway, but not via the ERa/ERß pathways.

\section{INTRODUCTION}

Men have 3-4 times higher incidence of bladder cancer (BC) than women [1]. Although approximately
$80 \%$ of patients are present with non-muscle-invasive $\mathrm{BC}$ (NMIBC) at the initial diagnosis, $36-51 \%$ of them recur despite of currently available adjuvant instillation therapy, such as intravesical instillation of an anthracycline or 
bacillus Calmette-Guérin (BCG), and approximately 10\% of them eventually progressed to muscle invasion [2]. In addition, developments in treatment modalities for $\mathrm{BC}$ did not result in an improvement in disease mortality rates for several decades [3]. Therefore, new treatment is urgently needed to prevent both recurrence and progression of BC.

Using preclinical models, we and others have revealed the involvement of androgen receptor (AR) signaling in $\mathrm{BC}$ development [4-6]. However, prognostic significance of $\mathrm{AR}$ expression in $\mathrm{BC}$ recurrence is still controversial [7-11]. Moreover, there is no significant gender-specific difference in the expression levels of AR [7], suggesting that circulating serum androgens may be critical for AR-stimulated BC development.

Recently, we demonstrated first clinical evidence indicating that androgen deprivation therapy (ADT) prevented $\mathrm{BC}$ recurrence [12]. In brief, in patients with double primary cancers of the prostate and bladder, ADT for their prostate cancer, mostly with a LHRH analogue, significantly reduced the risk of $\mathrm{BC}$ recurrence [hazard ratio (HR): 0.29]. LHRH analogues suppress secretion of follicle-stimulating hormone (FSH) and luteinizing hormone (LH) from the pituitary gland resulting in suppression of androgens from the testis. Since estrogens in men are mainly produced by aromatization of testosterone, LHRH analogue deprives estrogens as well [13]. Estrogens-mediated estrogen receptor (ER) signals have also been implicated in BC development [14-16]. Even in men, estrogens whose serum levels are similar to those in postmenopausal women have physiological functions, such as bone health, regulation of body fat, and sexual function [17].

Thus, whether AR signals were responsible for the preventive effect of $\mathrm{ADT}$ on $\mathrm{BC}$ recurrence was still open question. The purpose of this study is to investigate the associations between $\mathrm{AR} / \mathrm{ER} \alpha / \mathrm{ER} \beta$ expression in surgical specimens and $\mathrm{BC}$ recurrence in patients treated with ADT.

\section{RESULTS}

\section{$A R / E R \alpha / E R \beta$ expression in tumors and corresponding normal tissues}

We immunohistochemically evaluated $72 \mathrm{BCs}$ and 42 corresponding normal tissues for the expression of AR, ER $\alpha$, and ER $\beta$. Positive signals for all three receptors were detected predominantly in the nuclei of neoplastic (Figure 1) or non-neoplastic (figure not shown) urothelial cells. $\mathrm{AR} / \mathrm{ER} \alpha / \mathrm{ER} \beta$ were positive in $44(61 \%) / 22(31 \%) / 39(54 \%)$ tumors and $35(83 \%) / 24(57 \%) / 34(81 \%)$ corresponding normal-appearing urothelial tissues, respectively. In accordance with our previous findings [7], AR $(P=$ $0.020) / \operatorname{ER} \alpha(P=0.006) / \operatorname{ER} \beta(P=0.005)$ expression was significantly lower in tumors than in non-neoplastic urothelial tissues.

\section{Patient characteristics}

$\mathrm{AR} / \mathrm{ER} \alpha / \mathrm{ER} \beta$ expression in BCs and corresponding normal tissues, in relation to patient/tumor characteristics, is shown in Tables 1 and 2. There were no statistically significant correlations between each receptor expression in tumors or normal tissues and clinicopatholgical features of BCs.

\section{Expression of AR, ER $\alpha$, and ERß in BCs and tumor recurrence}

We next performed Kaplan-Meier analyses coupled with log-rank tests to assess possible associations between staining of AR, ER $\alpha$, and $\mathrm{ER} \beta$ in BCs and tumor recurrence. With a median follow-up of 31.3 months, 12 (43\%) of 28 patients with AR-negative tumor versus 11 (23\%) of 44 patients with AR-positive tumor experienced $\mathrm{BC}$ recurrence. Median time to recurrence was 8.2 (interquartile range [IQR]: 4.7-20.4) months. Thus, patients with AR-positive tumor had a significantly lower
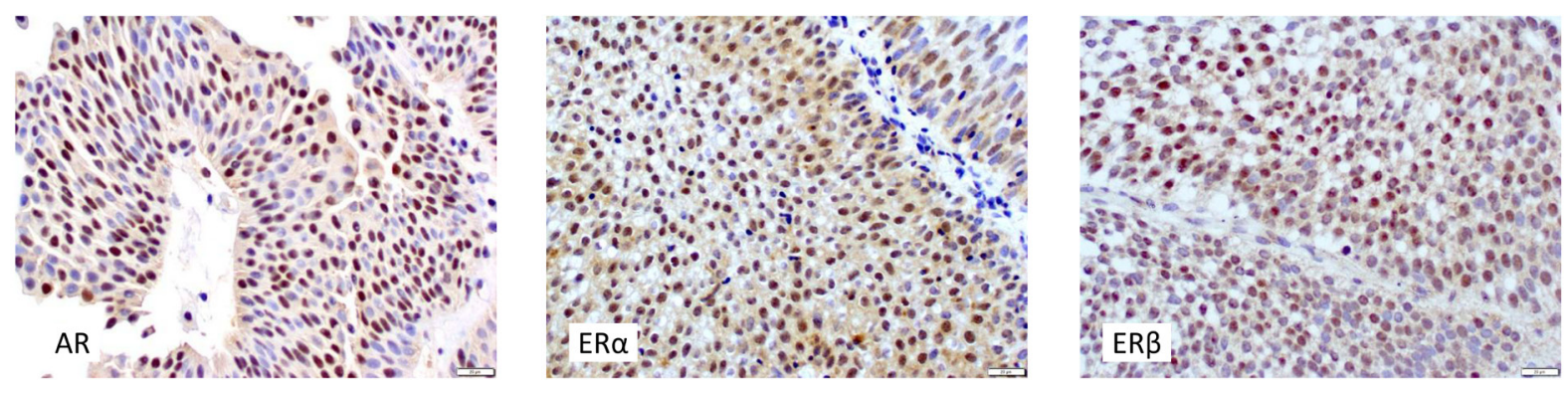

Figure 1: Immunohistochemistry of AR, ER $\boldsymbol{\alpha}$, and $\mathbf{E R} \boldsymbol{\beta}$ in urothelial tumors. Original magnification: $x 400$. 
Table 1: Correlations between $A R / E R \alpha / E R \beta$ expression in tumors and clinicopathological features of BC Characteristics $A R(-), n(\%) \quad A R(+), n(\%) \quad P \quad E R a(-), n(\%) \quad E R a(+), n(\%)$

\begin{tabular}{|c|c|c|c|c|c|c|}
\hline No. & $28(38.9)$ & $44(61.1)$ & $50(69.4)$ & $22(30.6)$ & $33(45.8)$ & $39(54.2)$ \\
\hline
\end{tabular}

\begin{tabular}{|c|c|c|c|c|c|c|c|c|c|}
\hline Tumor grade & & & 0.867 & & & 0.436 & & & 0.691 \\
\hline 1 & $6(21.4)$ & $12(27.3)$ & & $11(22.0)$ & $7(31.8)$ & & $7(21.2)$ & $11(28.2)$ & \\
\hline 2 & $14(50.0)$ & 18 (40.9) & & $21(42.0)$ & $11(50.0)$ & & 17 (51.5) & $15(38.5)$ & \\
\hline 3 & $7(25.0)$ & $11(25.0)$ & & $14(28.0)$ & $4(18.2)$ & & $8(24.2)$ & $10(25.6)$ & \\
\hline Not applicable & $1(3.6)$ & $3(6.8)$ & & $4(8.0)$ & $0(0)$ & & $1(3.0)$ & $3(7.7)$ & \\
\hline Pathological T stage & & & 0.555 & & & 0.477 & & & 0.762 \\
\hline pTa & $23(82.1)$ & $31(70.5)$ & & $36(72.0)$ & $18(81.8)$ & & $26(78.8)$ & $28(71.8)$ & \\
\hline pT1 & $4(14.3)$ & $10(22.7)$ & & $10(20.0)$ & $4(18.2)$ & & $6(18.2)$ & $8(20.5)$ & \\
\hline $\mathrm{pTis}$ & $1(3.6)$ & $3(6.8)$ & & $4(8.0)$ & $0(0)$ & & $1(3.0)$ & $3(7.7)$ & \\
\hline Tumor size & & & 0.252 & & & 1.000 & & & 0.257 \\
\hline$<3 \mathrm{~cm}$ & $24(85.7)$ & $32(72.7)$ & & $39(78.0)$ & 17 (77.3) & & $28(84.8)$ & $28(71.8)$ & \\
\hline$\geq 3 \mathrm{~cm}$ & $4(14.3)$ & $12(27.3)$ & & $11(22.0)$ & $5(22.7)$ & & $5(15.2)$ & $11(28.2)$ & \\
\hline Tumor number & & & 0.809 & & & 0.443 & & & 0.637 \\
\hline Single & $15(53.6)$ & $21(47.7)$ & & $27(54.0)$ & $9(40.9)$ & & $18(54.5)$ & $18(46.2)$ & \\
\hline Multiple & $13(46.4)$ & $23(52.3)$ & & $23(46.0)$ & $13(59.1)$ & & 15 (45.5) & $21(53.8)$ & \\
\hline Concomitant $\mathrm{CIS}$ & & & 0.471 & & & 0.421 & & & 0.275 \\
\hline No & $26(92.9)$ & $38(86.4)$ & & $43(86.0)$ & $21(95.5)$ & & 31 (93.9) & $33(84.6)$ & \\
\hline Yes & $2(7.1)$ & $6(13.6)$ & & $7(14.0)$ & $1(4.5)$ & & $2(6.1)$ & $6(15.4)$ & \\
\hline Intravesical instillation & & & 0.352 & & & 0.747 & & & 1.000 \\
\hline No & $16(57.1)$ & $20(45.5)$ & & $24(48.0)$ & $12(54.5)$ & & $17(51.5)$ & $19(48.7)$ & \\
\hline Anthracycline & $9(32.1)$ & 13 (29.5) & & $15(30.0)$ & $7(31.8)$ & & $10(30.3)$ & $12(30.8)$ & \\
\hline BCG & $3(10.7)$ & $11(25.0)$ & & $11(22.0)$ & $3(13.6)$ & & $6(18.2)$ & $8(20.5)$ & \\
\hline
\end{tabular}

Abbreviations: CIS, carcinoma in situ; BCG, Bacillus Calmette-Guérin.

(A)

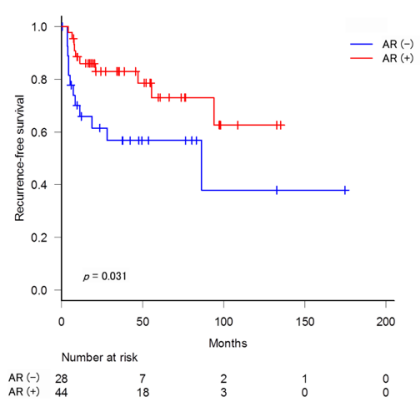

(B)

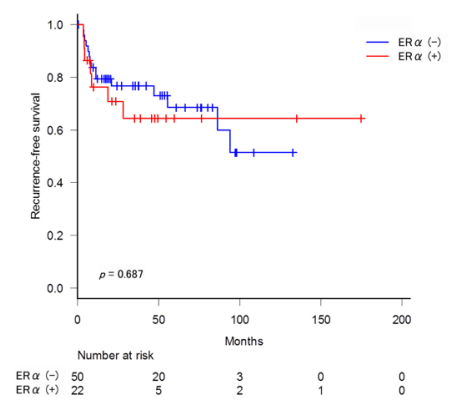

(C)

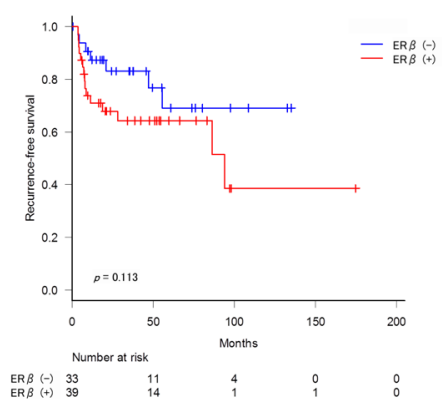

Figure 2: Recurrence-free survival according to the expression of $A R / E R \alpha / E R \beta$ in tumors. 
Table 2: Correlations between AR/ERa/ERß expression in normal urothelial tissues and clinicopathological features of $\mathrm{BC}$

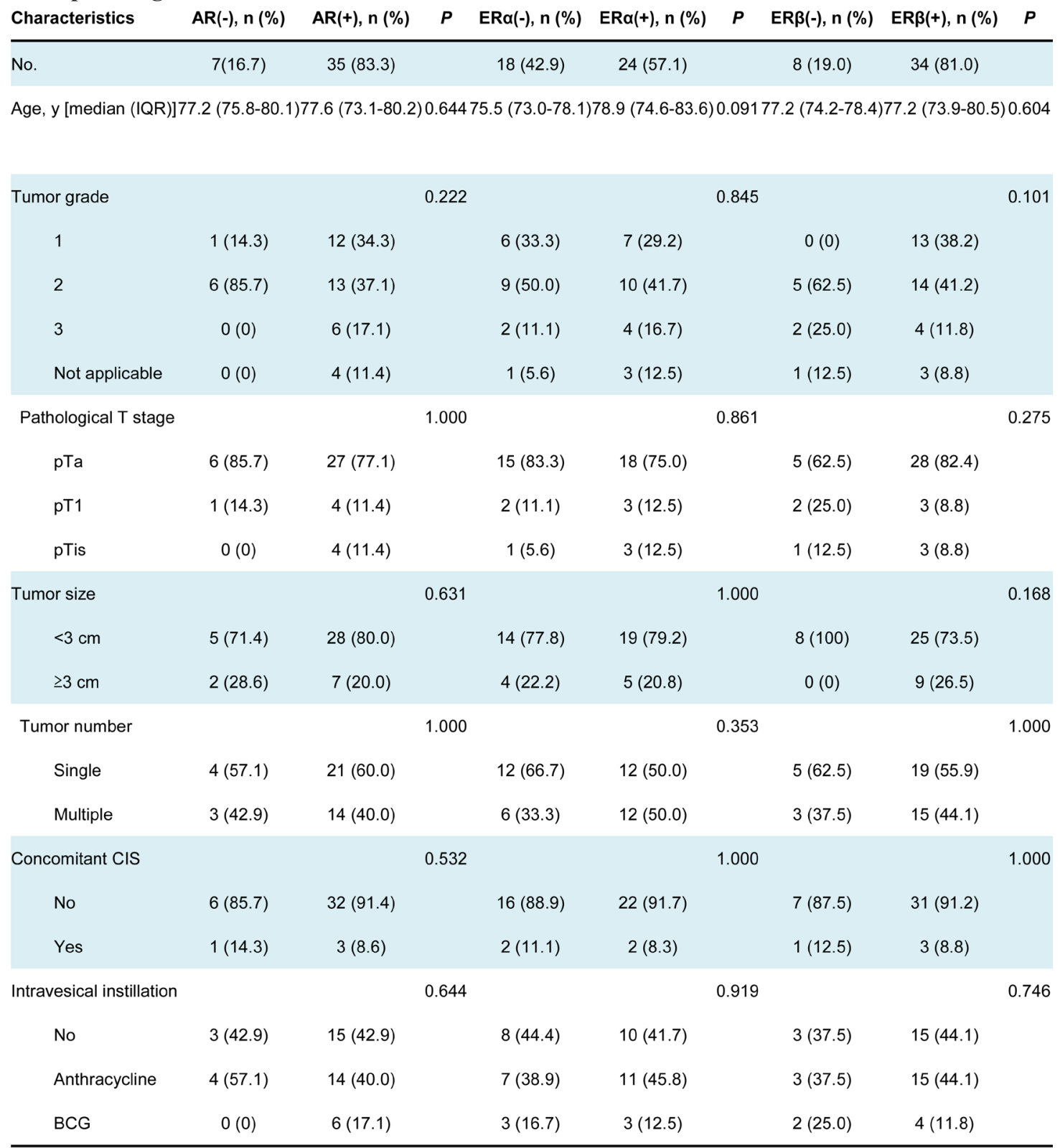

Abbreviations: CIS, carcinoma in situ; BCG, Bacillus Calmette-Guérin.

Table 3: Univariate and multivariate analyses for $\mathrm{BC}$ recurrence in ADT patients

\begin{tabular}{|c|c|c|c|c|}
\hline \multirow[b]{2}{*}{ Variables } & \multicolumn{2}{|l|}{ Univariate } & \multicolumn{2}{|c|}{ Multivariate } \\
\hline & HR $(95 \% \mathrm{Cl})$ & $\boldsymbol{P}$ & HR $(95 \% \mathrm{Cl})$ & $\boldsymbol{P}$ \\
\hline Age, continuous value & $1.05(0.98-1.13)$ & 0.178 & $1.07(0.99-1.15)$ & 0.076 \\
\hline AR expression (positive vs. negative) & $0.35(0.15-0.84)$ & 0.018 & $0.27(0.11-0.67)$ & 0.005 \\
\hline Tumor grade (3 vs. 1,2$)$ & $0.99(0.36-2.72)$ & 0.984 & & \\
\hline Tumor stage (pT1 vs. pTa) & $0.63(0.19-2.15)$ & 0.461 & & \\
\hline Tumor size $(\geq 3 \mathrm{~cm}$ vs. $<3 \mathrm{~cm})$ & $1.61(0.58-4.45)$ & 0.359 & & \\
\hline Tumor number (multiple vs. single) & $2.05(0.85-4.98)$ & 0.111 & $3.12(1.22-7.95)$ & 0.017 \\
\hline Carcinoma in situ (yes vs. no) & $1.23(0.29-5.30)$ & 0.782 & & \\
\hline Intravesical instillation (yes vs. no) & $0.59(0.23-1.46)$ & 0.252 & & \\
\hline
\end{tabular}


risk of $\mathrm{BC}$ recurrence (5-year actuarial recurrence-free survival: $73 \%$ v $57 \% ; P=0.031$, Figure $2 \mathrm{~A}$ ), compared with those with AR-negative tumor. On the other hand, $\mathrm{ER} \alpha$ (Figure $2 \mathrm{~B}$ ) or ER $\beta$ (Figure $2 \mathrm{C}$ ) positivity in tumors did not significantly correlate with tumor recurrence.

To see whether AR expression was an independent predictor of recurrence, multivariate analysis was performed with Cox model, including AR positivity and other well-known clinicopathological risk factors for $\mathrm{BC}$ recurrence (Table 3 ). Of these, AR positivity (HR: $0.27 ; 95 \%$ confidence interval (CI): 0.11-0.67) as well as multiple tumor (HR: 3.12; 95\%CI: 1.22-7.95) was found to be an independent prognosticator of $\mathrm{BC}$ recurrence.

\section{Expression of AR, ER $\alpha$, and ER $\beta$ in corresponding normal tissues and tumor recurrence}

Since de novo tumorigenesis is considered to be one of the mechanisms for $\mathrm{BC}$ recurrence, we then investigated associations between $\mathrm{AR} / \mathrm{ER} \alpha / \mathrm{ER} \beta$ expression in corresponding normal urothelial tissues and tumor recurrence. However, as shown in Figure 3, any of receptor expression in normal tissues did not significantly correlate with tumor recurrence.

\section{DISCUSSION}

In the current study, we investigated very specific patients with double primary cancers of the bladder and prostate who received ADT for their prostate cancer and showed that AR positivity in BCs correlated with a reduced risk of tumor recurrence. These findings strongly support that AR signals contributed to the preventive effect of ADT on $\mathrm{BC}$ recurrence. On the other hand, similar to the results in patients without ADT [7], ER $\beta$ positivity in tumors showed a marginally higher risk of recurrence, suggesting that ER $\beta$ expression is not associated with the preventive effect of ADT but may be an independent prognosticator on $\mathrm{BC}$ recurrence. Consistent with our previous observations [7], ER $\alpha$ expression did not predict $\mathrm{BC}$ recurrence, suggesting no significant correlation between ER $\alpha$ signals and the ADT effect.

Although a recent review article introduced some clinical trials of new targeted therapies for $\mathrm{BC}$, none of these were approved for BC treatment to date [18]. The authors assumed the lack of patient stratification by each target expression led underestimation of the efficacy of these new therapies. In our previous study [12], although we did not stratify the patients by AR expression, ADT surprisingly prevented BC recurrence with HR of 0.29. The current study then suggests that appropriate patient selection further improves the efficacy of AR inactivation in $\mathrm{BC}$ treatment at least for preventing recurrence of NMIBC.

For the treatment of prostate cancer, there are two major ways to target AR signals; surgical/chemical castration and anti-androgens. Castration is often associated with reduced health-related quality of life (e.g. fatigue, loss of physical capacity, emotional distress and sexual function) and bone mineral density, compared with anti-androgen monotherapy [19]. Therefore, anti-androgen monotherapy is an alternative for nonmetastatic locally advanced prostate cancer, although castration with or without anti-androgen is the standard procedure. Although phase I trial targeting AR in muscleinvasive BC was initiated in the US [20], to the best of our knowledge, prospective studies for NMIBC have not yet been performed. As an adjuvant therapy, anti-androgen monotherapy might be better than castration in terms of adverse effects for the future clinical trials. Furthermore, AR knockdown in urotehlial cells by intravesical instillation of antisense oligonucleotides, as shown with those of heat shock protein 27 in $\mathrm{BC}$ [21], is a potential
(A)

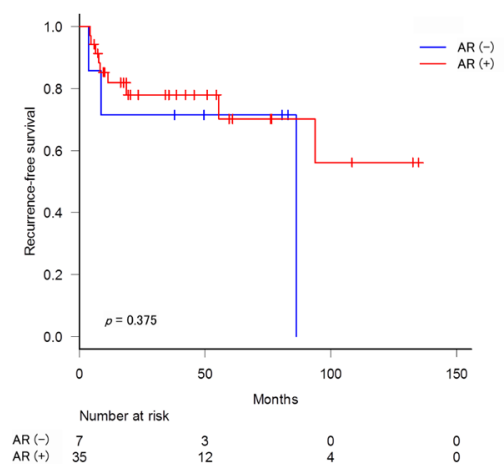

(B)

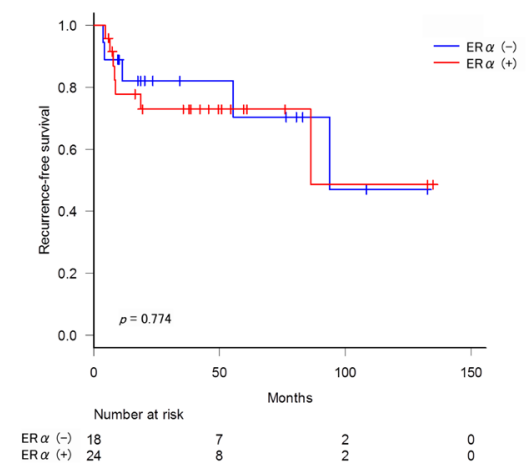

(C)

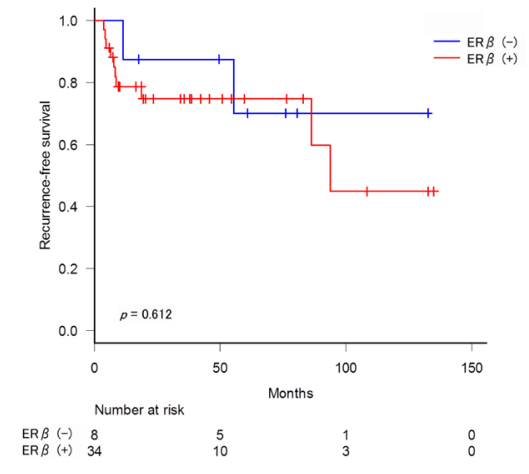

Figure 3: Recurrence-free survival according to the expression of $A R / E R \alpha / E R \beta$ in normal tissues. 
treatment option to avoid systemic adverse effects associated with ADT currently used for the treatment of prostate cancer.

Recently, some large-scale genome-wide profiling studies proposed new classifications of BC [22-25]. Interestingly, these independent studies showed significant overlaps which improved understanding of molecular features of BC [26]. Among these molecules, epidermal growth factor receptor/ERBB2 [27], Wnt/ $\beta$-catenin [28], p53 [29], UDP-glucuronosyltransferase-1A [30], CD24 [31], GATA3 [32], and Slug [33] are shown to be activated or inhibited by AR signals in BC or non-neoplastic urothelial cells. In addition, recent studies have revealed the association between AR signals and Nur77 [34], ELK1 [35], or IL-8 [36] in BC. It is thus likely that AR signals contribute to modulating multiple independent pathways in BC cells.

AR expression as a predictor of better prognosis seen in the present study appears to be contrary to the tumor promoting effect of AR signals in BC [4-6]. A potential reason is that AR signals and other pathways complementarily stimulate BC development. Controversial results of an association between AR expression in BCs and their recurrence [7-11] support this hypothesis. If that is the case, when patients receive ADT, BC recurrence is induced by other pathways that are more dominant in ARnegative tumor compared with AR-positive tumor.

A recent retrospective study involving patients who received ADT for prostate cancer showed a significantly lower incidence of subsequent BC development [37]. In addition, a large scale prospective study revealed that finasteride reduced the risk of $\mathrm{BC}$ [38]. These clinical findings support the involvement of $\mathrm{AR} / \mathrm{ER} \alpha / \mathrm{ER} \beta$ signals in bladder tumorigenesis. Since de novo tumorigenesis might be one of the causes of $\mathrm{BC}$ recurrence, we also investigated associations between $\mathrm{AR} / \mathrm{ER} \alpha / \mathrm{ER} \beta$ expression in corresponding normal urothelial tissues and tumor recurrence. Since biopsy of normal urothelial tissues was not routinely performed, the sample size was much smaller than that of $\mathrm{BC}$ tissues. Consistent with our previous observations [7], there were no statistically significant correlations between each receptor expression in corresponding urothelial tissues and clinicopatholgical features of BC. Furthermore, any of receptor expression in corresponding urothelial tissues did not significantly correlate with tumor recurrence. This is possibly because: 1) tumor dissemination is more dominant way of recurrence; 2) adjacent urothelial tissues are no longer normal; or 3 ) the sample size is too small. Further investigation using larger sample size is needed to confirm the correlations between the expression of steroid hormone receptors in normal urothelium and $\mathrm{BC}$ recurrence.

The main limitations of the current study include its retrospective design with limited study population. However, since the incidence of primary BC in prostate cancer patients in our cohort was only $1.2 \%$ [12] and only a subset of the patients received ADT for their prostate cancer, a prospective cohort study involving men with double cancers may not be practical. Future clinical trials determining the efficacy of ADT in BC recurrence are still needed to confirm our findings.

\section{CONCLUSIONS}

We here report the expression of AR, but not ER $\alpha$ or $\mathrm{ER} \beta$, in $\mathrm{BC}$ is associated with tumor recurrence in patients treated with ADT. Together with our previous observations, ADT with anti-androgen monotherapy and/ or LHRH analogue is suggested to prevent $\mathrm{BC}$ recurrence via the AR pathway. In addition, AR expression in $\mathrm{BC}$ can be a useful marker in selecting patients for ADT.

\section{PATIENTS AND METHODS}

\section{Tissue samples}

We retrospectively retrieved $72 \mathrm{BCs}$ and 42 corresponding normal urothelial tissues obtained by transurethral resection from patients who received ADT for their prostate cancer from 2001 to 2012 in four hospitals (Yokohama City University Hospital, Yokohama City University Medical Center, Yokohama Municipal Citizen's Hospital, and International Goodwill Hospital). Fifteen patients received LHRH monotherapy whereas others received combined androgen blockade consisting of LHRH analogue and anti-androgen. Median duration of ADT was 25.7 (IQR: 9.8-55.1) months. None of these patients received systemic chemotherapy or underwent radical cystectomy. Appropriate approval from the institutional review board at each institution was obtained before use of the tissue samples.

\section{Immunohistochemistry}

Immunohistochemical staining was performed, as described previously [7]. Sections (4 $\mu \mathrm{m}$ thick) were immunohistochemically labeled, using a primary antibody to AR (N20 clone, dilution 1:100; Santa Cruz Biotechnology, Santa Cruz, CA, USA), ER $\alpha$ (E115 clone, dilution 1:100; Epitomics, Burlingame, CA, USA), and ER $\beta$ (14C8 clone, dilution 1:50; Abcam, Cambridge, MA, USA). All the stains were manually scored by one pathologist (H.M.) blinded to patient identity. The expression of each receptor was considered positive when more than $10 \%$ of urothelial tumor cells or non-neoplastic urothelial cells were immunoreactive or at least $1 \%$ of urothelial tumor cells or non-neoplastic urothelial cells showed moderate to strong intensity [7]. 


\section{Statistical analyses}

The Fisher exact test was used to evaluate the association between categorized variables. Nonparametric two group comparison was carried out using MannWhitney $U$ test to assess differences in continuous variables. Survival rates in patients were calculated by the Kaplan-Meier method, and comparison was made by log-rank test. The Cox proportional hazards model was used to determine statistical significance of predictors in a multivariate setting. $P<0.05$ was considered to be statistically significant. All statistical analyses were performed with EZR (Saitama Medical Center, Jichi Medical University, Saitama, Japan), which is a graphical user interface for $\mathrm{R}$ (The $\mathrm{R}$ Foundation for Statistical Computing, Vienna, Austria). More precisely, it is a modified version of $\mathrm{R}$ commander designed to add statistical functions frequently used in biostatistics.

\section{ACKNOWLEDGMENTS}

We thank Tamiyo Taniguchi and Rie Shimizu for her assistance in tissue preparation.

\section{CONFLICTS OF INTEREST}

The authors have no conflicts of interest to disclose.

\section{REFERENCES}

1. Torre LA, Bray F, Siegel RL, Ferlay J, Lortet-Tieulent J, Jemal A. Global cancer statistics, 2012. CA Cancer J Clin. 2015; 65: 87-108.

2. Shang PF, Wang ZP, Tian JH, Jiang L, Yang KH, Yue ZJ, Tian JQ. Intravesical Bacillus Calmette-Guérin versus epirubicin for Ta and T1 bladder cancer. Cochrane Database Syst. Rev. 2008; CD006885.

3. Abdollah F, Gandaglia G, Thuret R, Schmitges J, Tian Z, Jeldres C, Passoni NM, Briganti A, Shariat SF, Perrotte P, Montorsi F, Karakiewicz PI, Sun M. Incidence, survival and mortality rates of stage-specific bladder cancer in United States: a trend analysis. Cancer Epidemiol. 2013; 37: 21925.

4. Miyamoto $H$, Yang Z, Chen $Y$-T, Ishiguro $H$, Uemura $H$, Kubota Y, Nagashima Y, Chang Y-J, Hu Y-C, Tsai M-Y, Yeh S, Messing EM, Chang C. Promotion of bladder cancer development and progression by androgen receptor signals. J Natl Cancer Inst. 2007; 99: 558-68.

5. Li Y, Izumi K, Miyamoto H. The role of the androgen receptor in the development and progression of bladder cancer. Jpn J Clin Oncol. 2012; 42: 569-77.

6. Miyamoto H, Zheng Y, Izumi K. Nuclear hormone receptor signals as new therapeutic targets for urothelial carcinoma. Curr Cancer Drug Targets. 2012; 12: 14-22.
7. Miyamoto H, Yao JL, Chaux A, Zheng Y, Hsu I, Izumi K, Chang C, Messing EM, Netto GJ, Yeh S. Expression of androgen and oestrogen receptors and its prognostic significance in urothelial neoplasm of the urinary bladder. BJU Int. 2012; 109: 1716-26.

8. Tuygun C, Kankaya D, Imamoglu A, Sertcelik A, Zengin K, Oktay M, Sertcelik N. Sex-specific hormone receptors in urothelial carcinomas of the human urinary bladder: a comparative analysis of clinicopathological features and survival outcomes according to receptor expression. Urol Oncol. 2011; 29: 43-51.

9. Nam JK, Park SW, Lee SD, Chung MK. Prognostic value of sex-hormone receptor expression in non-muscle invasive bladder cancer. Yonsei Med J. 2014; 55: 1214.

10. Mashhadi R, Pourmand G, Kosari F, Mehrsai A, Salem S, Pourmand MR, Alatab S, Khonsari M, Heydari F, Beladi L, Alizadeh F. Role of steroid hormone receptors in formation and progression of bladder carcinoma: a case-control study. Urol J. 2014; 11: 1968-73.

11. Mir C, Shariat SF, van der Kwast TH, Ashfaq R, Lotan Y, Evans A, Skeldon S, Hanna S, Vajpeyi R, Kuk C, Alkhateeb $\mathrm{S}$, Morote J, van Rhijn BWG, et al. Loss of androgen receptor expression is not associated with pathological stage, grade, gender or outcome in bladder cancer: a large multi-institutional study. BJU Int. 2011; 108: 24-30.

12. Izumi K, Taguri M, Miyamoto H, Hara $Y$, Kishida $T$, Chiba K, Murai T, Hirai K, Suzuki K, Fujinami K, Ueki T, Udagawa K, Kitami K, et al. Androgen deprivation therapy prevents bladder cancer recurrence. Oncotarget. 2014; 5: 12665-74. doi: 10.18632/oncotarget.2851.

13. Falahati-Nini A., Riggs BL, Atkinson EJ, O'Fallon WM, Eastell R, Khosla S. Relative contributions of testosterone and estrogen in regulating bone resorption and formation in normal elderly men. J Clin Invest. 2000; 106: 1553-60.

14. Hsu I, Yeh C, Slavin S, Miyamoto H, Netto GJ, Tsai Y, Muyan M, Wu X, Messing EM, Guancial EA, Yeh S. Estrogen receptor alpha prevents bladder cancer via INPP4B inhibited akt pathway in vitro and in vivo. Oncotarget. 2014; 5: 7917-35. doi: 10.18632/ oncotarget.1421.

15. Hsu I, Chuang K-L, Slavin S, Da J, Lim W-X, Pang S-T, O'Brien JH, Yeh S. Suppression of ER $\beta$ signaling via ER $\beta$ knockout or antagonist protects against bladder cancer development. Carcinogenesis. 2014; 35: 651-61.

16. Hsu I, Vitkus S, Da J, Yeh S. Role of oestrogen receptors in bladder cancer development. Nat Rev Urol. 2013; 10: 317 26.

17. Finkelstein JS, Lee H, Burnett-Bowie SA, Pallais JC, Yu EW, Borges LF, Jones BF, Barry CV, Wulczyn KE, Thomas BJ, Leder BZ. Gonadal steroids and body composition, strength, and sexual function in men. N Engl J Med. 2013; 369: 1011-22.

18. van Kessel KEM, Zuiverloon TCM, Alberts AR, Boormans JL, Zwarthoff EC. Targeted therapies in bladder cancer: an 
overview of in vivo research. Nat Rev Urol. 2015; 12: 68194.

19. Smith MR, Goode M, Zietman AL, McGovern FJ, Lee $\mathrm{H}$, Finkelstein JS. Bicalutamide monotherapy versus leuprolide monotherapy for prostate cancer: effects on bone mineral density and body composition. J Clin Oncol. 2004; 22: 2546-53.

20. H. Lee Moffitt Cancer Center and Research Institute. Enzalutamide in Combination With Gemcitabine and Cisplatin in Bladder Cancer. In: ClinicalTrials.gov. Bethesda (MD): National Library of Medicine (US). 2000. Available from: http://clinicaltrials.gov/show/ NCT02300610. NLM Identifier NCT02300610.

21. Ischia J, So AI. The role of heat shock proteins in bladder cancer. Nat Rev Urol. 2013; 10: 386-95.

22. Sjödahl G, Lauss M, Lövgren K, Chebil G, Gudjonsson S, Veerla S, Patschan O, Aine M, Fernö M, Ringnér M, Månsson W, Liedberg F, Lindgren $\mathrm{D}$, et al. A molecular taxonomy for urothelial carcinoma. Clin Cancer Res. 2012; 18: $3377-86$.

23. Damrauer JS, Hoadley KA., Chism DD, Fan C, Tiganelli CJ, Wobker SE, Yeh JJ, Milowsky MI, Iyer G, Parker JS, Kim WY. Intrinsic subtypes of high-grade bladder cancer reflect the hallmarks of breast cancer biology. Proc Natl Acad Sci U S A. 2014; 111: 3110-5.

24. Choi W, Porten S, Kim S, Willis D, Plimack ER, HoffmanCensits J, Roth B, Cheng T, Tran M, Lee I-L, Melquist J, Bondaruk J, Majewski T, et al. Identification of distinct basal and luminal subtypes of muscle-invasive bladder cancer with different sensitivities to frontline chemotherapy. Cancer Cell. 2014; 25: 152-65.

25. Weinstein JN, Akbani R, Broom BM, Wang W, Verhaak RGW, McConkey D, Lerner S, Morgan M, Creighton CJ, Smith C, Kwiatkowski DJ, Cherniack AD, Kim J, et al. Comprehensive molecular characterization of urothelial bladder carcinoma. Nature. 2014; 507: 315-22.

26. Knowles MA, Hurst CD. Molecular biology of bladder cancer: new insights into pathogenesis and clinical diversity. Nat Rev Cancer. 2015; 15: 25-41.

27. Zheng $\mathrm{Y}$, Izumi $\mathrm{K}$, Yao JL, Miyamoto $\mathrm{H}$. Dihydrotestosterone upregulates the expression of epidermal growth factor receptor and ERBB2 in androgen receptor-positive bladder cancer cells. Endocr Relat Cancer. 2011; 18: 451-64.

28. Li Y, Zheng Y, Izumi K, Ishiguro H, Ye B, Li F, Miyamoto $\mathrm{H}$. Androgen activates $\beta$-catenin signaling in bladder cancer cells. Endocr Relat Cancer. 2013; 20: 293-304.

29. Hsu J-W, Hsu I, Xu D, Miyamoto H, Liang L, Wu X-R, Shyr C-R, Chang C. Decreased tumorigenesis and mortality from bladder cancer in mice lacking urothelial androgen receptor. Am J Pathol. 2013; 182: 1811-20.

30. Izumi K, Zheng Y, Hsu J, Chang C, Miyamoto H. Androgen receptor signals regulate UDP-glucuronosyltransferases in the urinary bladder: A potential mechanism of androgen- induced bladder carcinogenesis. Mol Carcinog. 2013; 52: 94-102.

31. Overdevest JB, Knubel KH, Duex JE, Thomas S, Nitz MD, Harding MA, Smith SC, Frierson HF, Conaway M, Theodorescu D. CD24 expression is important in male urothelial tumorigenesis and metastasis in mice and is androgen regulated. Proc Natl Acad Sci U S A. 2012; 109: E3588-96.

32. Li Y, Ishiguro H, Kawahara $\mathrm{T}$, Miyamoto $\mathrm{Y}$, Izumi $\mathrm{K}$, Miyamoto H. GATA3 in the urinary bladder: suppression of neoplastic transformation and down-regulation by androgens. Am J Cancer Res. 2014; 4: 461-73.

33. Jing Y, Cui D, Guo W, Jiang J, Jiang B, Lu Y, Zhao W, Wang X, Jiang Q, Han B, Xia S. Activated androgen receptor promotes bladder cancer metastasis via Slug mediated epithelial-mesenchymal transition. Cancer Lett. 2014; 348: 135-45.

34. Wu J, Liu J, Jia R, Song H. Nur77 inhibits androgenInduced bladder cancer growth. Cancer Invest. 2013; 31 : 654-60.

35. Kawahara T, Shareef HK, Aljarah AK, Ide H, Li Y, Kashiwagi E, Netto GJ, Zheng Y, Miyamoto H. ELK1 is up-regulated by androgen in bladder cancer cells and promotes tumor progression. Oncotarget. 2015; 6: 2986076. doi: 10.18632/oncotarget.5007.

36. Ou Z, Wang Y, Liu L, Li L, Yeh S, Qi L, Chang C. Tumor microenvironment B cells increase bladder cancer metastasis via modulation of the IL-8/androgen receptor (AR)/MMPs signals. Oncotarget. 2015; 6: 26065-78. doi: 10.18632/oncotarget.4569.

37. Shiota M, Yokomizo A, Takeuchi A, Imada K, Kiyoshima K, Inokuchi J, Tatsugami K, Ohga S, Nakamura K, Honda H, Naito S. Secondary bladder cancer after anticancer therapy for prostate cancer: reduced comorbidity after androgen-deprivation therapy. Oncotarget. 2015; 6: 147109. doi: 10.18632/oncotarget.3817.

38. Morales EE, Grill S, Svatek RS, Kaushik D, Thompson IM, Ankerst DP, Liss MA. Finasteride reduces risk of bladder cancer in a large prospective screening study. Eur Urol. 2016; 69: 407-10. 